\title{
The Role of the Ministry Of Foreign Affairs Of The Bureaucracy and Diplomats in Decision-making Process in Turkey
}

\author{
Hasan Hakses \\ Selcuk University
}

\begin{abstract}
The decision-making process is a theoretical conclusion that involves moving / implementing actions in the light of the possibilities of what options will reflect in the light of the analysis of the present findings to show the states / crises or politics that the states that are accepted as international actors in the context of the decision-making theory (Hermann, 2001). Allison argues that in the analysis of the decision-making process, it is the Rational Actor Model, the Organizational Process Model and the Bureaucratic Model (Allison,1971). According to Allison, while the decisionmaking process is being analyzed, these three models need to be evaluated together to achieve a healthy outcome. It emphasizes the necessity of studying more case studies for better understanding of the process. It would not be rational to apply / adapt the information obtained to other countries because the work done in this area is mostly US based (Hermann, 2001).

The idea behind this work is to discuss the extent to which the approaches in the literature can be adapted to Turkey, which is changing in the governmental system. The general structure of the Turkish Ministry of Foreign Affairs, which plays an important role in the process before the evaluation of the foreign policy of Turkey, will be tried to be analyzed in the historical frame of the diplomats and the approaches of the Ministry bureaucracy during the decision making process.
\end{abstract}

Keywords: Leader-Centered Policy, Turkish Foreign Policy. 